\title{
Stroke and the Extracranial Carotid Arteries: Role of Color Doppler
}

\author{
Authors \\ Dr B.B.Panda ${ }^{1}$, Dr Subhasish Mohapatra ${ }^{2}$, Dr Savitri Bhagat ${ }^{3}$, Dr Subhasish Panda ${ }^{4}$, \\ Dr Anurag Das ${ }^{5}$, Dr Subhashree Dash ${ }^{6}$, Dr Keshaba Panigrahy ${ }^{7}$ \\ ${ }^{1}$ Assoc. Prof, Dept of Radiodiagnosis, VIMSAR, Burla, India \\ ${ }^{2}$ Consultant Radiologist, Paras Imaging Centre, Noida, India \\ ${ }^{3}$ Prof \& HOD, Dept of Radiodiagnosis, VIMSAR, Burla, India \\ ${ }^{4,5,6,7}$ PG Student, Dept of Radiodiagnosis, VIMSAR, Burla, India \\ Corresponding Author \\ Dr. Subhasish Panda \\ Email:drsubhasishpanda15@gmail.com
}

\begin{abstract}
Aims and Objectives: This study was carried out with the aims to find out the age, sex and various risk factors in patients of ischemic stroke and to know the distribution of territory of the brain infarction and study the association of carotid artery atherosclerosis.

Results: Hypertensive males in the age group of 61-70 years of age were the most common patients. Stenosis of Carotid Arteries was found in 24 (48\%) out of 50 cases.

Conclusion: Carotid Doppler can be used for early detection, quantification and characterization of extracranial atherosclerosis and occlusive disease

Keywords: Middle Cerebral, Lacunar, Intimomedial, Stenosis.
\end{abstract}

\section{Introduction}

Stroke is a leading cause of death in India and the world. It is defined by WHO as rapidly developing clinical signs of focal/ global disturbance of cerebral function with symptoms lasting more than 24 hours or leading to death with no apparent cause other than that of vascular origin. The leading cause of stroke is Atherosclerosis and its presence within the carotid arteries is an important predictor of artery to artery embolism. Duplex Ultrasound of the Carotids provides a fast, portable, noninvasive and inexpensive means for vascular diagnosis of ischemic stroke.

\section{Material \& Methods}

The study was carried out on 50 patients within 2 years (March 2010- March 2012) from medical and neurological wards of V.S.S medical college, Burla with provisional diagnosis of stroke.

The patients whose initial ct study showed infarction were included in the study and those with hemorrhagic stroke and stroke mimic were excluded. The patients whose carotid doppler study could not be done due to death or other reason were also excluded from the study.

Clinical information was noted down from the referral papers and additional clinical history from the relatives and attendants. The initial ct scan was done with Siemens somatom emotion 16 - slice ct 
scanner in VSS medical college and hospital and cases confirmed with ischaemic stroke were included in the study.

Next the cases were subjected to carotid doppler study with Larsen and Toubro sequina color doppler with 6.6-14 MHZ transducer. Both grey scale and color doppler (duplex and spectral study) were done in order : CCA, ICA and ECA.

Intimo media thickness (IMT) was recorded. When a stenosis was present, angle corrected spectral wave form was taken within the area of maximum stenosis. The morphology and ultrasound characteristic of plaques (when present) were recorded. The observed PSVs, the ratio of PSV in ICA to that in CCA and the EDVS were then used to estimate the degree of stenosis.

These findings were then reviewed with the presenting age and sex, signs and symptoms of the patients before drawing any conclusion and giving the final report.

\section{Observation}

Initial NECT confirmed cases of ischaemic stroke were evaluated for carotid artery diseases with color duplex ultrasonography.

Table 1 Age and Sex Distribution in Ischemic Stroke

\begin{tabular}{|c|c|c|c|c|}
\hline Age group (years) & Male & Female & Total & Percentage \\
\hline$<30$ & 2 & 2 & 4 & 8 \\
\hline $31-40$ & 2 & 1 & 3 & 6 \\
\hline $41-50$ & 3 & 2 & 5 & 10 \\
\hline $51-60$ & 7 & 3 & 10 & 20 \\
\hline $61-70$ & 10 & 7 & 17 & 34 \\
\hline $71-80$ & 5 & 3 & 8 & 16 \\
\hline$>80$ & 2 & 1 & 3 & 6 \\
\hline
\end{tabular}

\section{Table 2 Risk Factors}

\begin{tabular}{|l|c|c|c|c|}
\hline Risk Factors & Male & Female & Total & $\%$ \\
\hline Hypertension & 19 & 12 & 31 & 62 \\
\hline Diabetes & 14 & 8 & 22 & 44 \\
\hline Hypercholesterolemia & 7 & 2 & 9 & 18 \\
\hline Smoking & 14 & 0 & 14 & 28 \\
\hline
\end{tabular}

Table 3 Neurological Deficit in cases of Ischemic Stroke

\begin{tabular}{|l|c|c|}
\hline Neurologic Deficit & No of Cases & $\%$ \\
\hline Hemiplegia/Hemiparesis & 34 & 68 \\
\hline Monoplegia & 1 & 2 \\
\hline Aphasia/ Dysphasia & 11 & 22 \\
\hline Visual disturbances & 3 & 6 \\
\hline Others & 23 & 46 \\
\hline
\end{tabular}

Table 4. Distribution \& Mean Age in 50 cases of ischemic Stroke with and without Carotid Lesion

\begin{tabular}{|l|c|c|}
\hline & No. of Patients & $\begin{array}{l}\text { Mean Age +- } \\
\text { SD (in years) }\end{array}$ \\
\hline No Lesion & 26 & $54.2+-18.5$ \\
\hline Lesion Present & 24 & $66.4+-9.19$ \\
\hline
\end{tabular}

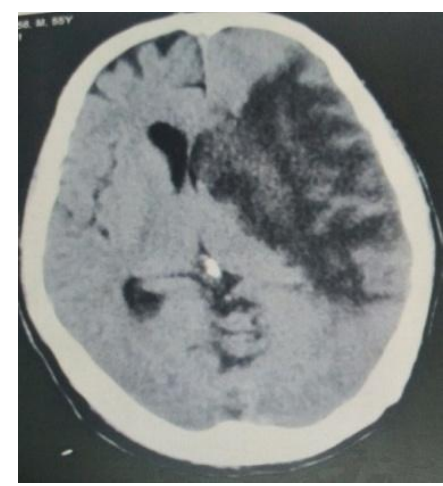

Fig 1 CT Scan demonstrating left MCA territory infarct.

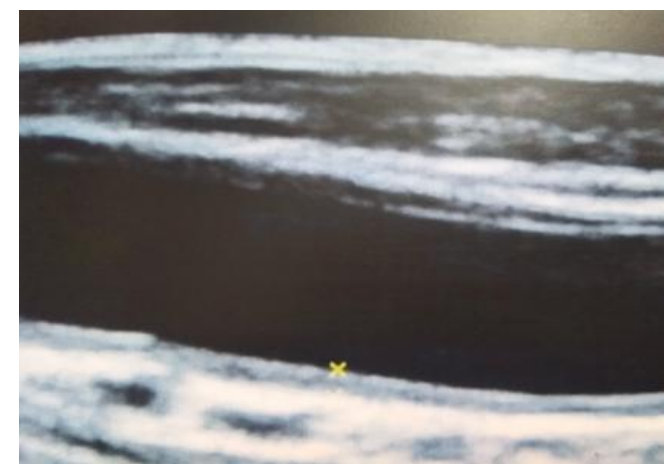

Fig 2 Carotid Ultrasound shows increased intimomedial thickness.

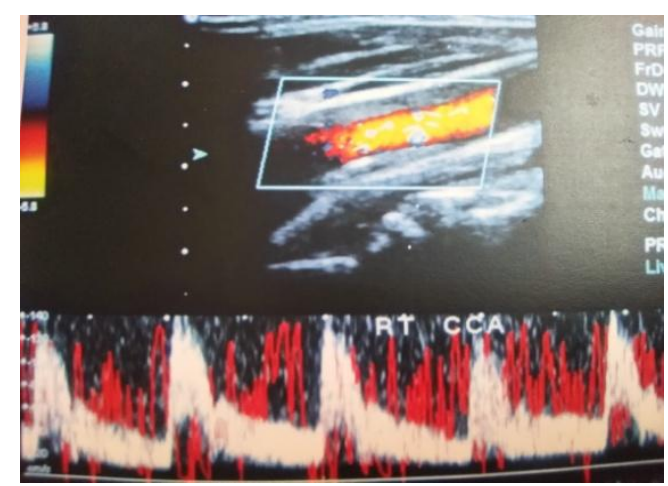

Fig 3 Carotid Doppler shows increased PSV and EDV in stenotic region of Common Carotid Artery (CCA).

\section{Discussion}

In the present study (table 1) maximum number of cases (17 i.e 34\% of the total) belonged to the age group 61-70. This was in accordance with Millikan 
$\mathrm{CH}, \mathrm{McDowell} \mathrm{F}$, Easton et al and Carroll BA et al (1).

The incidence of ischaemic stroke below the age of 40 years was $14 \%$ (i.e $7 \%$ ). This was higher than that reported by Raskin and Weiss from USA (2.8\%) but, the incidence in India has been reported to be higher by Naik et al(18.8\%), Gupta et al and Dalal et al $(23.6 \%)^{(2,3)}$.This sheds light on the higher incidence of ischemic stroke in the young in India.

In the present study (table 1) : 62\% of cases were male and $38 \%$ of cases were female. This correlates with observation of S.S. Mishra et $a l^{(4)}$.

In the present study (table 2) hypertension was found in $62 \%$ ( 31 cases) followed by diabetes $44 \%$ (22 cases) and next followed by smoking in 28\%(14 cases).Hypertension as an important risk factor for atherosclerosis and stroke was found in Framingham study (1965), Los Angeles study and by Abraham et al $(1970)^{(5)}$. The result is consistent with Agrawal et al $(54.9 \%)$ and Dalal et al(2005) ${ }^{(3)}$. Diabetes was found in 22 cases i.e $44 \%$ in our study. In the present study i.e table 3,the most common neurological deficit - hemiplegia or hemiparesis was found in 34 cases (i.e 68\%) and in accordance with study by Abraham et al(1970) and Chopra et al $(1979)^{(5,6)}$.

The most common CT finding was an acute cortical infarction seen in 27 cases (i.e54\%) and the second most common finding was lacunar infarction seen in 14 cases i.e $28 \%$ and was accordance with study done by Regli L et al $1993^{(7)}$.

Hemorrhagic stroke accounted for 3 cases i.e $6 \%$ and was correlated to study by Ladurner $\mathrm{G}$ et al and Regli L et al (15-25\%) who found the same finding $(7,8)$.

The most common vascular territory involved was the middle cerebral artery territory, found in 37 cases i.e $74 \%$ is well correlated with Osborn AG et al $(75 \%)^{(9)}$. The second most common was Posterior Cerebral Artery territory in 5 cases $(10 \%)$ and close to the study by Ladurner et $\mathrm{al}^{(8)}$.

In the present study : the maximum number of patients with carotid stenosis were in age group 6170 (11 out of 24) (45.8\%) and equal number in 5160 year and $71-80$ year with $20.8 \%$ each. No stenosis was seen below 40 years age group. This is because, principal causes of stroke in the young are extracranial arterial dissection, cardioembolism, haematological and immunological disorders, mitochondrial diseases, etc. most of which may not harbor an abnormality of the extracranial Carotids (10). The mean age of patients with carotid stenosis was 66.4 and without carotid stenosis was 54.2.The difference was statistically significant and correlated with Sethi et al ${ }^{(11)}$.

As is shown in Table 4, no atherosclerotic plaque was found in 26 cases $(52 \%)$ while carotid stenosis was seen in 24 cases $(48 \%)$.

Male patients were more than female patients and correlated with Forster et and Sethi et al ${ }^{(11,12)}$.

Increased intimo media thickness (IMT) was seen in total $29 \%$ of cases out of which $25 \%$ were above 60 years of age. Vicenzini et al observed a stong positive correlation between IMT and increased age (13)

Overall IMT for males was higher than females and correlated with Ebrahim et al ${ }^{(14)}$.

Out of total 100 arteries (including bilateral carotids in same patient), 35 plaques were found. Out of 35 plaques, $14.3 \%$ were hypoechoic, $54 \%$ were hyperechoic, $31.4 \%$ were calcified and this correlated with Petrovic et al ${ }^{(15)}$.

\section{Conclusion}

Ischaemic stroke is a common cause of morbidity and mortality with a maximum incidence in males of age group 50-70 years. Risk factors of the same include hypertension, diabetes mellitus, smoking, etc. which can be modified to reduce the incidence, morbidity and mortality of ischemic stroke. Duplex ultrasound is a fast, portable, non invasive, repeatable and inexpensive technique for vascular diagnosis of ischaemic stroke. It can be used for early detection, quantification and characterization of extracranial atherosclerosis and occlusive disease, especially at the carotid bifurcation. 


\section{References}

1. Carroll BA et al. Carotid ultrasound. Neuroimaging clinics of North America. (1996), 6(4):875-897.

2. Gupta PD et al. Cerebrovascular accident. A clinical analysis of 260 cases. Indian Heart journal(1965), 17:57.

3. Dalal pm et al Strokes (CVA) in India. Jap Circul J 1982; 46:621-4. Correlates of stroke in Community. Journal of Indian Academy of Clinical Medicine. (1998); 5(1):27-31.

4. Mishra SS, Agrawal RN, Silcar PS; Cerebrovascular disease, A review of 458 consecutive cases, Journal of Indian Medical Association, 967, 48:528.

5. Abraham J, Rao PSS, Inbaraj SG, Shetty G et al. An epidemiological study of hemiplegia due to stroke in South India. Stroke (1970)1:477-81.

6. Chopra JS, Pravakar S et al : Clinical features and risk factors in stroke in India; Acta. Neurol.Scand (1979)60:289

7. Regli L, Regli $F$ et al. Magnetic Resonance Imaging With Gadolinium Contrast Agent in Small Deep (Lacunar) Cerebral Infarcts; Arch Neurol. (1993);50(2):175-180.

8. Ladurner G, Sager WD, Iliff LD, Lechner H et al. A Correlation of Clinical Findings and CT in Ischaemic Cerebrovascular Disease. Eur Neurology(1979);18:281-288.

9. Osborn AG: Diagnostic Neuroradiology. 1994.

10. P. J. Martin, T. P. Enevoldson, and P. R. Humphrey. Causes of ischaemic stroke in the young. Postgrad Med J. 1997 Jan; 73(855): 8-16.

11. Sethi SK, Solanki RS, Gupta H et al Color and Duplex Doppler imaging evaluation of extracranial carotid artery in patients presenting with transient ischaemic attack and stroke - a clinical and radiological correlation. Indian Journal of Radiology and Imaging. 2005; 15(1):91-98

12. Foster A, Gass A, Kern R, Wolf ME et al. Gender Differences in Acute Ischemic
Stroke Etiology, Stroke Patterns and Response to Thrombolysis; Stroke(2009), 40:2428-2432.

13. Vincenzini E, Giannoni MF, Ricciardi MC, Toscano $\mathrm{M}$ et al. Non invasive Imaging of Carotid Arteries in Stroke: Emerging Value of Real- time High- Resolution Sonography in Carotid Occlusion Due to Cardiac Embolism; J ultrasound med (2010); 29:1635-1941.

14. Ebrahim S, Papacosta O, Whincup P, Wannamethee $G$ et al. Carotid Plaque, Intima Media Thickness, Cardiovascular Risk Factors, and Prevalent Cardiovascular Disease in Men and Women: The British Regional Heart Study Stroke. (1999);30:84150 .

15. Petrovic S, Petrovic D, Rancic Z, Zivkovic $\mathrm{M}$ et al. The significance of Color Doppler Sonography in selection of patients for carotid endarterectomy: Acta facultatis medical Naissensis. (2006) vol.23(1),31-38. 